\title{
Graphene oxide modified screen-printed electrode for highly sensitive and selective electrochemical detection of ciprofloxacin residues in milk
}

\author{
Ming Pan ${ }^{1,2^{*}+}$, Peipei Guo ${ }^{2 \dagger}$, Haifeng Liu ${ }^{1,2}$, Jiawei Lu² and Qiubo Xie ${ }^{1,2}$
}

\begin{abstract}
The monitoring of antibiotic residues in foodstuffs by using rapid detection method is essential for food safety. In this work, the electrochemical sensor was developed by modification of screen-printed carbon electrode with graphene oxide, and then the ciprofloxacin (CIP) was detected based on the complexation of CIP with $\mathrm{Mn}^{2+}$. On modified electrode, the anodic stripping peak current response of $\mathrm{Mn}^{2+}$ was prohibited in the presence of CIP, and a peak current response of the complex was occurred. Thus, the peak current response of the complexation peak was employed as the indicating signal for CIP determination, which was more sensitive than the direct electrochemical oxidation response of CIP. Parameters that affect the signal response have been investigated in method. Under the optimum conditions, the peak current of the complexation peak was linearly correlated with the CIP content in the milk sample solution at 1.0 to $8.0 \mu \mathrm{M}$, and the linear correlation coefficients $\left(R^{2}\right)$ was 0.994 . The limits of detection (LOD) was $0.30 \mu \mathrm{M}$. Recoveries of CIP in milk sample were ranged from 81.0 to $95.4 \%$ with relative standard deviations (RSDs) below $4.6 \%$. The method showed high selectivity and sensitive, good reproducibility, indicated that this method has potential to be applied in CIP residue analysis.
\end{abstract}

Keywords: Graphene oxide, Screen-printed electrode, Electrochemical analysis, Ciprofloxacin

\section{Introduction}

The widespread use and abuse of antibiotics contribute to the production of multidrug-resistant microorganisms and unhealthy animal derived foods, which has become a growing threat to public health and a global problem announced by WHO (Zhang et al. 2018, 2020; Zheng et al. 2019). Ciprofloxacin (CIP), a synthetic thirdgeneration quinolone antibacterial drug, is widely used in in the treatment of diseases in human life and livestock industry because of its remarkable sterilization effect

\footnotetext{
*Correspondence: costa_pan@126.com

${ }^{\dagger}$ Ming Pan and Peipei Guo contributed equally to this work

${ }^{1}$ Guangdong Institute of Modern Agricultural Equipment, No. 261

Wushan Road, Tianhe District, Guangzhou 510630, China

Full list of author information is available at the end of the article
}

(Van Doorslaer et al. 2014; Cheng et al. 2020; Wang et al. 2016). However, for high water solubility, easy migration and poor biodegradability under different $\mathrm{pH}$, the use of CIP has a series of negative effects such as contaminating environment and agricultural products (Aminov 2009). Therefore, it is necessary to use improved analytical methods to monitor CIP in environmental and food samples, so as to provide support for environmental protection, food health risk assessment and antibiotic residues control (Bitew and Amare 2020).

Common techniques for determining antibiotics in environmental and food samples include high performance liquid chromatography (HPLC) coupled with various types of detector (Bekoe et al. 2014; Liu et al. 2005), spectroscopy (Abdulghani et al. 2013), and microbiological assays (Mendez et al. 2005). Problems associated with 
these technologies include the need for derivatization or time-consuming extraction procedures, a large number of organic solvents commonly used for extraction, expensive instruments and skilled personnel (Bitew and Amare 2020). Due to the advantages of easy miniaturization, high sensitivity, simplicity and relatively low cost, electrochemical detection has became an attractive alternative method for detecting electroactive substances (such as CIP) in food matrix (Ambaye et al. 2021). However, the direct electro-analysis of substances was still faced with complicated issues such as slow electron transfer dynamics, scaling on the electrode surface and high over potentials in the application of this kind of traditional electrode (Zhang et al. 2012). In view of this, many improved electrodes have been proposed to improve the selectivity and sensitivity of CIP determination (Ghanbari and Hajian 2017; Zhao et al. 2019).

Printing electrode technologies, as the most advanced technologies for the manufacturing of versatile electronic equipment, are developing rapidly in recent years (Ankireddy et al. 2016). The printed electrodes are widely used in energy storage and conversion, electronic displays and smart electronic applications (Acuautla et al. 2014; Wei et al. 2021). In particular, the recently developed technology based on printed electrodes makes it possible to manufacture integrated electrodes which can be easily applied to electrochemical sensing applications (Hayat et al. 2013). Researchers have developed many technologies for manufacturing printed electrode materials including inkjet-printing, 3D printing and screen printing (Tortorich et al. 2018; Li et al. 2017). Based on the latest development of printed electrode technology, it is possible to replace the traditional non compact solid electrode with printed electrode sensor, which has the advantages of fast detection speed, low cost and easy transformation (Trojanowicz 2016).

The screen-printing carbon electrode (SPCE) technology uses a variety of mechanisms to coat materials materials, so as to achieve high sensitivity, selectivity and better compatibility (Wu et al. 2020). Adding nanostructures, such as conductive nano-polymers, carbon materials, metal nano-particles and redox mediators, is helpful to improve the excellent performance of electrodes and sensors (Ambaye et al. 2021). As a new twodimensional carbon material with selective molecular recognition, graphene oxide has many applications, such as solid-phase extraction, catalysis, and electrochemical sensors (Pumera et al. 2010). For electrochemical prospective, graphene oxide can enhance the selective accumulation of target substances, which in turn provides lower detection limit and good selectivity due to its high porosity, two dimensional amphiphilicity and interface surface area (Gan and Hu 2011).
Herein, graphene oxide with negative charges and large specific surface area was used to modify the screenprinted electrode to enhance the voltammetric response and simplify the procedure of application. A novel method for CIP determination was developed based on monitoring the peak current response of the complexation of CIP with $\mathrm{Mn}^{2+}$ by modified electrode. The effects of various experimental parameters in determination were investigated including $\mathrm{Mn}^{2+}$, interferents and $\mathrm{KCl}$. This study shows that the peak current response of the complexation of CIP with $\mathrm{Mn}^{2+}$ can be used as indicating signal for sensitive and selective determination of CIP, which overcome drawbacks of the conventional method such as low sensitivity and complicated electrode preparation process. Moreover, the recommended methods were successfully applied for the determination CIP in milk.

\section{Materials and methods}

Reagents and materials

Ciprofloxacin reference materials, graphene oxide and nafion solution (5\%) were obtained from Aladdin (Shanghai, China). Analytical reagents including phosphoric acid $\left(\mathrm{H}_{3} \mathrm{PO}_{4}\right)$, acetic acid ( $\left.\mathrm{HAc}\right)$ and boric acid $\left(\mathrm{H}_{3} \mathrm{BO}_{3}\right)$ were purchased from Guangzhou Chemical Reagent Factory. Triple-distilled water was used in experiment, and all other chemicals used in investigation were of analytical grade. The milk sample was obtained from a market in Tianhe, Guangzhou.

Individual CIP stock solution of $1000 \mathrm{mg} \mathrm{L}^{-1}$ was prepared by dissolving $0.010 \mathrm{~g}$ of CIP in $10 \mathrm{~mL}$ distilled water, stored at $4{ }^{\circ} \mathrm{C}$.

\section{Preparation of graphene oxide modified SPCE}

Graphene oxide powder (1.5 mg) was mixed into $1.0 \mathrm{~mL}$ of $0.01 \%$ nafion solution in isopropanol to obtain a $1.5 \mathrm{mg} \mathrm{mL}^{-1}$ graphene oxide suspension under ultrasonic treatment for $20 \mathrm{~min}$. Nafion act as a binding agent in this step, which helps the better adherence of graphene oxide on SPCE, thus improving the stability of the prepared electrode surface (Zhang et al. 2012). Prior to modification, bare SPCE was immersed in ultra-pure water for $5 \mathrm{~min}$ of ultrasonic cleaning. After being dried with nitrogen gas, the working area of SPCE was coated with $6.0 \mu \mathrm{L}$ of prepared graphene oxide suspension by using a micro-syringe. Then, the constructed electrode was incubated at $40^{\circ} \mathrm{C}$ for $5 \mathrm{~h}$ to obtain the graphene oxide modified SPCE (GO-SPCE).

\section{Determination procedure}

The electrochemical experiments were carried out on a CHI760E electrochemical work station (Chenhua, Shanghai) in a conventional three-electrode system. 
GO-SPCE, $\mathrm{Ag} / \mathrm{AgCl}$ electrode and platinum electrode were used as working, reference and auxiliary electrodes, respectively. Britton-Robinson (B-R) solution ( $\mathrm{pH}$ 8.0) was used as a supporting electrolyte for all the electrochemical experiments. The electrochemical behavior of GO-SPCE in B-R solution $(0.05 \mathrm{M}, \mathrm{pH}$ 8.0) was studied by using cyclic voltammetry (CV) and electrochemical impedance spectroscopy (EIS). The differential pulse anodic stripping voltammetry (DPSV) was used for electrochemical sensing of CIP under optimized conditions. The DPSV experiments were performed in potential range of $-0.1 \mathrm{~V}$ to $0.1 \mathrm{~V}$. The working solution of CIP with different concentrations were prepared by diluting stock solution with electrolyte solution.

\section{Results and discussion}

Effect of $\mathrm{Mn}^{2+}$ on electrochemical determination of CIP

It has been reported that a variety of metal ions can be used as complexing and sensitizing agent to enhance the peak current detection signal of CIP (Shan et al. 2015). In this experiment, the electrochemical performance of the GO modified SPCE (GO/SPCE) has been investigated by collecting CVs in $\mathrm{B}-\mathrm{R}$ solution ( $\mathrm{pH}$ 8.0) in presence and in absence of $\mathrm{Mn}^{2+}$. It can be seen that direct detection method is not feasible under this condition, CIP has no response without $\mathrm{Mn}^{2+}$ addition (Fig. 1A). After $\mathrm{Mn}^{2+}$ was added in the system, the peak current response at $0.4 \mathrm{~V}$, which contributed to the complexation of CIP with $\mathrm{Mn}^{2+}$, was remarkably enhanced (Fig. 1B). Moreover, the peak current response under different concentrations of CIP were investigated to ascertain that the peak
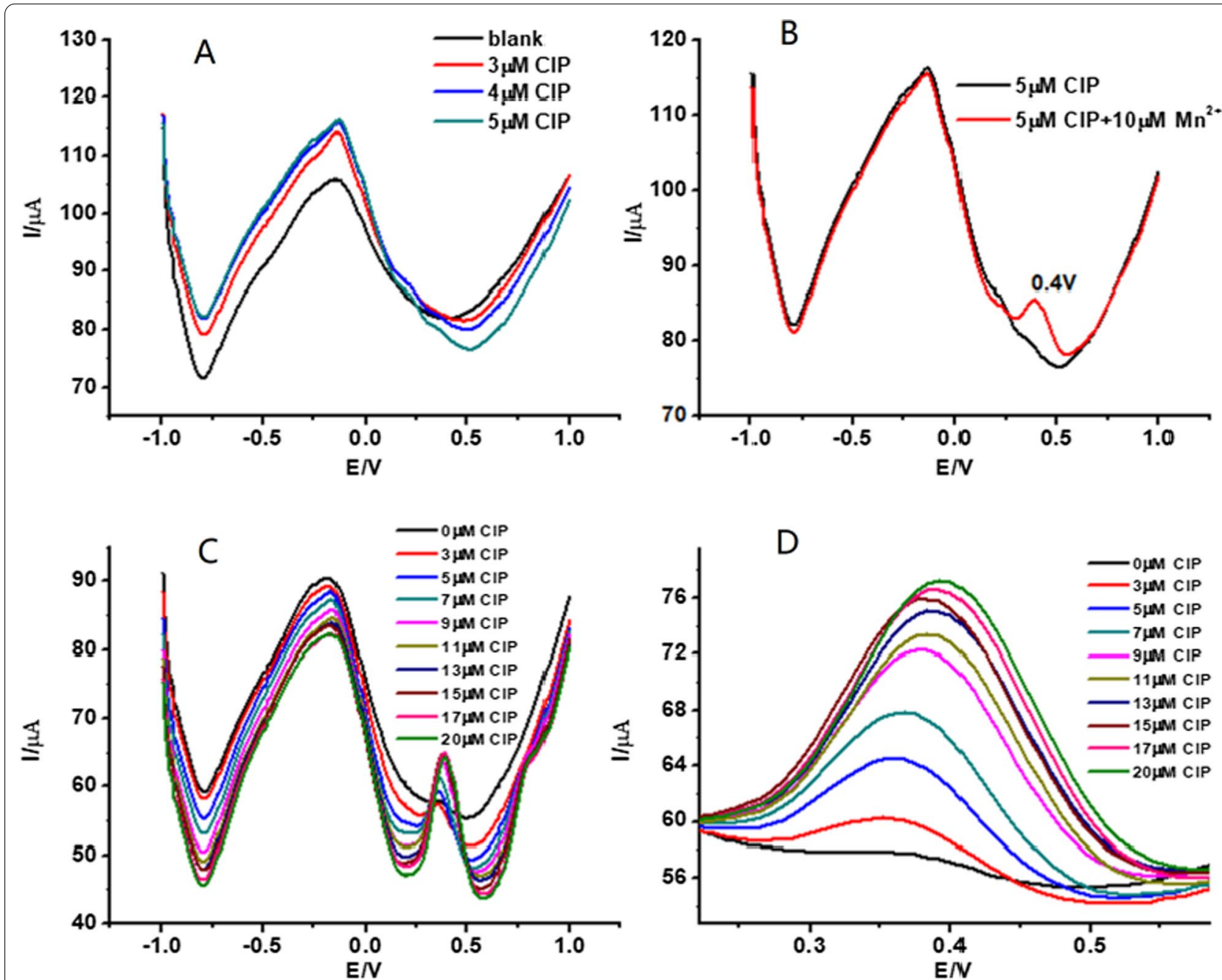

Fig. 1 Effect of $\mathrm{Mn}^{2+}$ on CIP determination. A Determination of CIP in the absence of $\mathrm{Mn}^{2+}$; $\mathbf{B}$ before and after adding $10 \mu \mathrm{M} \mathrm{Mn}{ }^{2+} ; \mathbf{C}$ differential pulse stripping voltammetry curves of CIP at concentration of 0-20 $\mu$ M; $\mathbf{D}$ a larger version of $\mathbf{C}$ 
current response at $0.4 \mathrm{~V}$ was caused by the formation of CIP and $\mathrm{Mn}^{2+}$ complex, and the results were shown in Fig. 1C and Fig. 1D. As can be seen in the figures, the peak current at $0.4 \mathrm{~V}$ increases with the increase of CIP concentration from 0 to $13 \mu \mathrm{M}$, indicating that there is a correlation between CIP concentration and the peak current response. However, the increase of peak current is gradually reduced while the concentration of CIP is increased from 13 to $20 \mu \mathrm{M}$, which might be due to the fact that adsorption shedding and the excessively adsorption of complex compounds on the electrode surface. The prepared electrode. has good analytical behavior at low concentration, which demonstrates its potential application prospect.

\section{Effect of interferents on determination of CIP}

The proposed GO-SPCE based method was applied to detect the CIP concentration when there are other interferents in sample solution for investigating the selectivity of this method. The peak current response in presence of $12 \mu \mathrm{M}$ of CIP was individually tested with different concentration of other compounds including glycine, glucose, sodium chloride $(\mathrm{NaCl})$ and ascorbic acid (vitamin C). The results shown in Fig. $2 \mathrm{~A}-\mathrm{C}$ showed that the peak potential and intensity of CIP complex will not be disturbed by glycine, glucose and $\mathrm{NaCl}$ at $120 \mu \mathrm{M}$ or $1200 \mu \mathrm{M}$ in the solution, indicating that the prepared GO-SPCE based sensor offers good selectivity for the determination of CIP. However, it was found that the addition of ascorbic acid could lead to a positive shift of the peak potential (Fig. 2D). These results indicated that the ascorbic acid in real sample have an adverse effect on the determination of CIP.

\section{Effect of $\mathrm{KCl}$ on determination of CIP}

Supporting electrolyte is a crucial factor influencing the peak current response. The effects of different $\mathrm{KCl}$ concentrations $(0,0.01,0.05,0.1 \mathrm{M})$ on peak current of

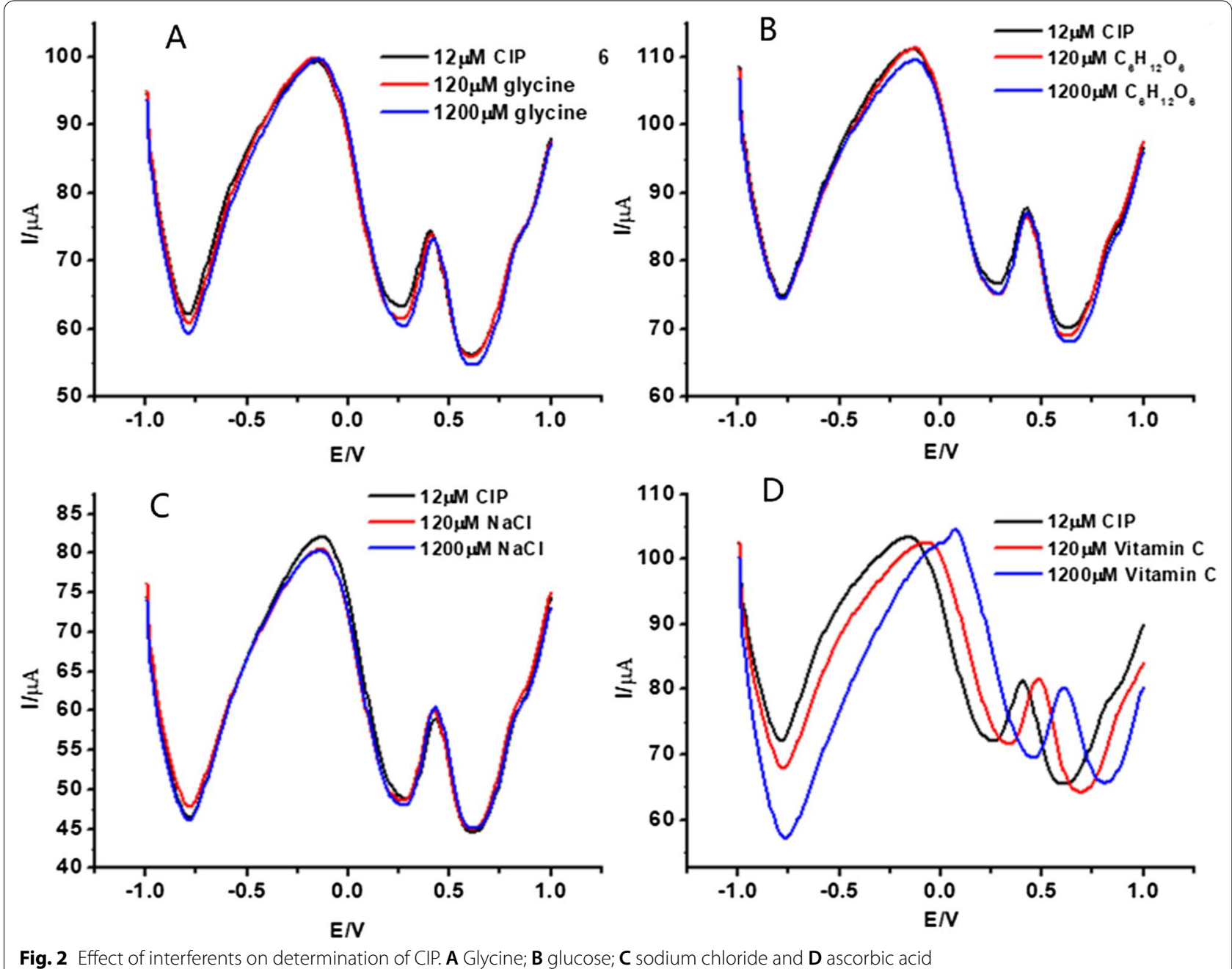

Fig. 2 Effect of interferents on determination of CIP. A Glycine; $\mathbf{B}$ glucose; $\mathbf{C}$ sodium chloride and $\mathbf{D}$ ascorbic acid 

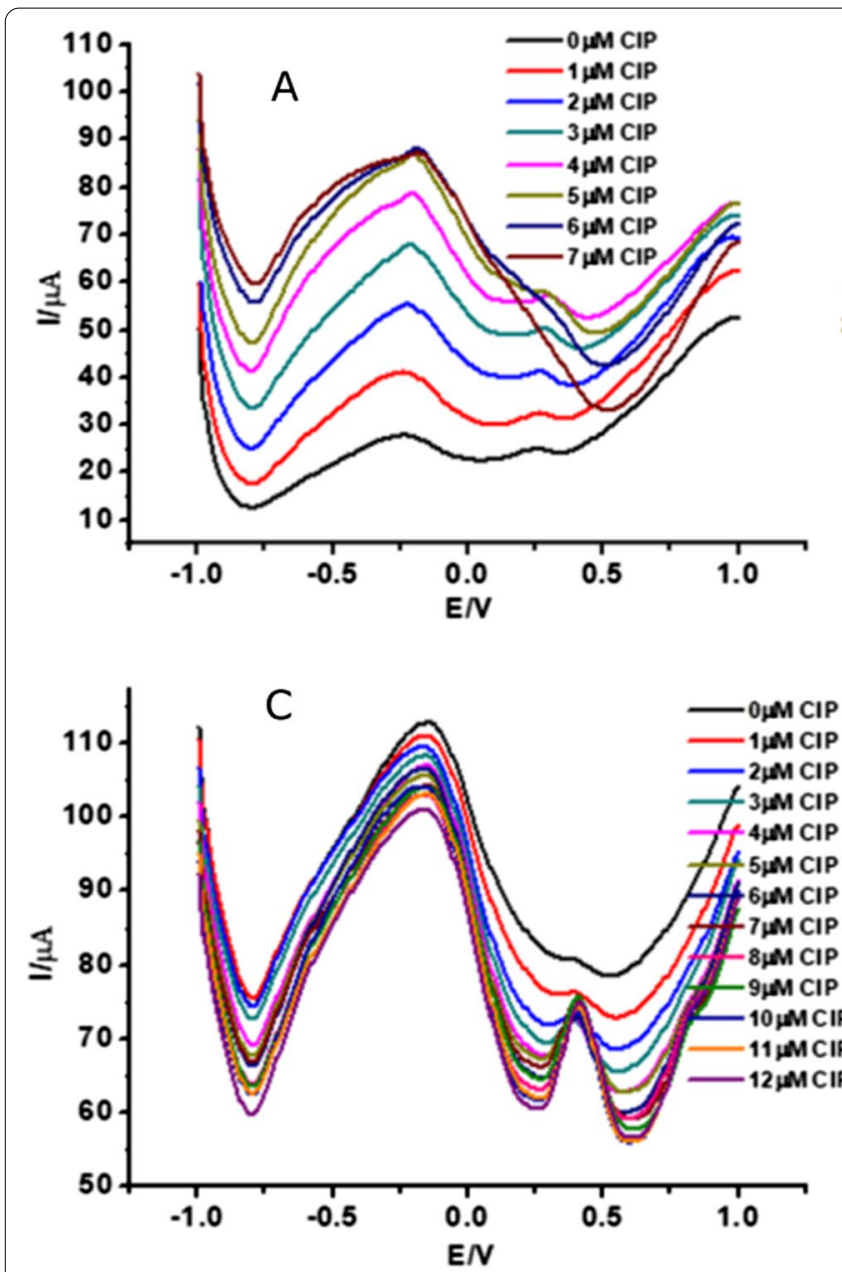
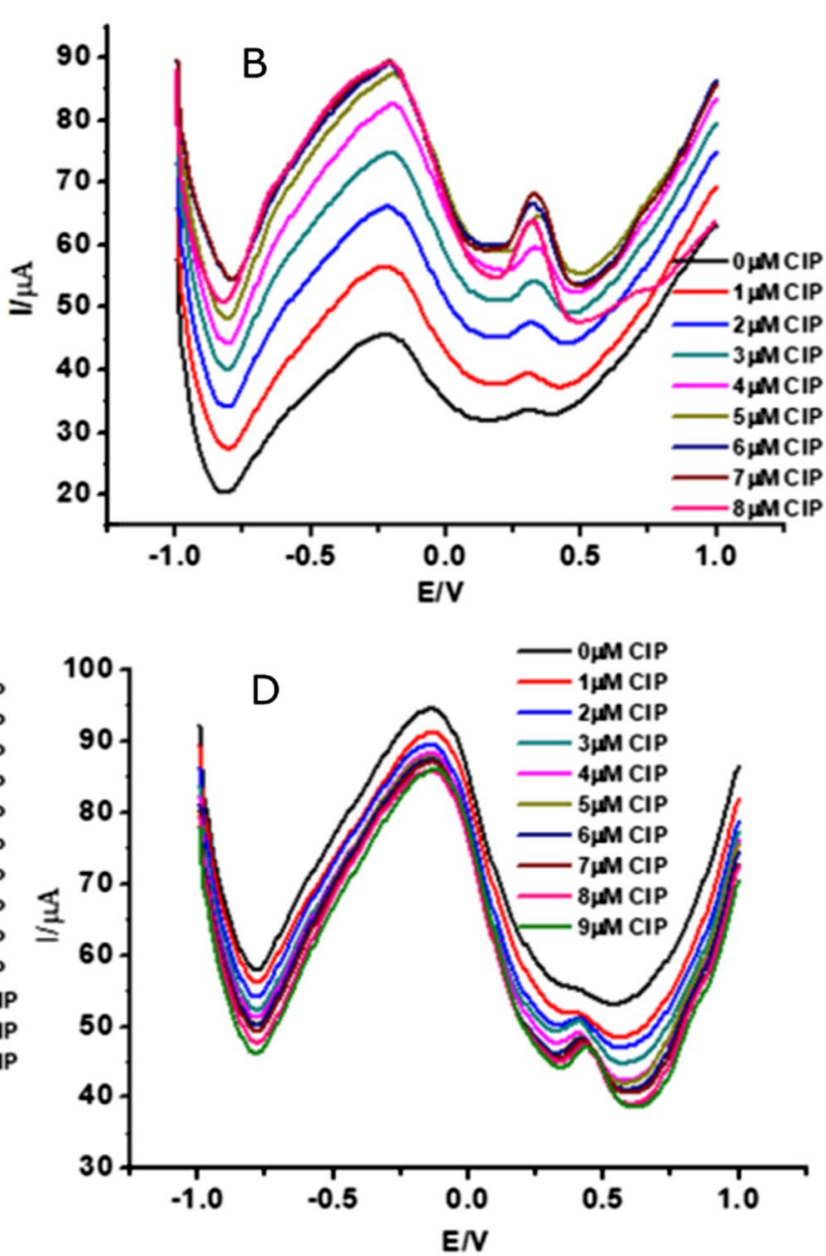

Fig. 3 Effect of $\mathrm{KCl}$ on determination of CIP. A 0 M; B 0.01 M; C 0.05 M; D 0.1 M

CIP complex were investigated in B-R solution ( $\mathrm{pH} 8.0$ ). As shown in Fig. 3, the peak current decreased with the increase of CIP concentration in the solution without $\mathrm{KCl}$, and the peak current background increased with the increase of CIP concentration when $0.01 \mathrm{M} \mathrm{KCl}$ was used. After that, 0.05 or $0.1 \mathrm{M} \mathrm{KCl}$ have better determination efficiency for CIP and selection of either concentration was reasonable. In this study, the $\mathrm{KCl}$ with optimized concentration of $0.05 \mathrm{M}$ created the best conditions for determination.

\section{Calibration procedure}

Calibration curve of CIP in B-R solution ( $\mathrm{pH}$ 8.0) has been obtained for the GO-SPCE under optimized conditions. The changes in the peak current response were recorded in terms of the potential values of the CIP complex to calculate the linear range of the proposed method response to the concentration of CIP. As shown in Fig. 4, the peak current value was linear with concentrations of

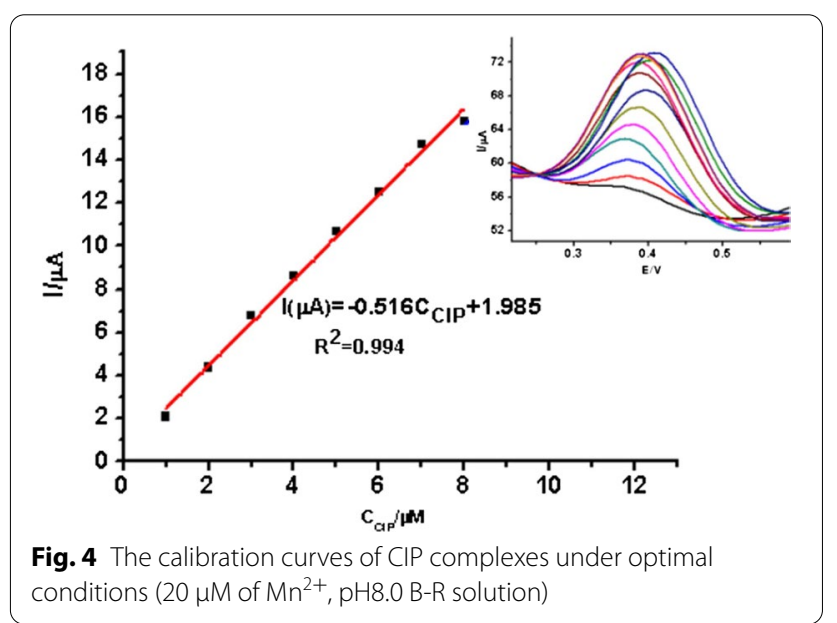


CIP in the range of 1.0 to $8.0 \mu \mathrm{M}$. The linear regression equation was expressed as $I(\mu \mathrm{A})=0.516 \mathrm{C}_{\mathrm{CIP}}+1.985$ (linear coefficient $R^{2}=0.994$ ). The limit of detection (LOD) $(3 \mathrm{~S} / \mathrm{N})$ was estimated to be $0.30 \mu \mathrm{M}$, which was lower than the maximum residue limit (MRL) of CIP in milk in China $\left(100 \mu \mathrm{g} \mathrm{kg}^{-1}\right)$.

\section{Application of proposed method in real milk sample}

The method was applied for the determination of CIP residues in milk sample. The blank milk sample was accurately weighed and dissolved in distilled water. After filtering, the filtrate was collected and diluted to $50 \mathrm{~mL}$ with $0.05 \mathrm{M} \mathrm{KCl}$ in B-R solution (pH 8.0) to prepare a sample solution. The sample solution was spiked with CIP at three concentration levels $(1.0,5.0,10.0 \mu \mathrm{M})$ to evaluate the accuracy of the method. Then $10 \mu \mathrm{M}$ of $\mathrm{Mn}^{2+}$ was added, and the peak current response was recorded for measuring the concentration of CIP. The results obtained from these experiments were summarized in Table 1, which shows the percentage of good recoveries, thus indicating the feasibility of the present method.

\section{Comparison with other methods}

The comparisons between this GO-SPCE based method and other electrochemical sensor techniques such as multi-walled carbon nanotubes/glassy carbon electrode (MWCNT/GCE), DNA biosensor, chitosan $/ \mathrm{Fe}_{3} \mathrm{O}_{4} /$ carbon paste electrode (Chitosan/ $/ \mathrm{Fe}_{3} \mathrm{O}_{4} / \mathrm{CPE}$ ) from the viewpoint of LOD and linear range were listed in Table 2. As can be seen, the GO-SPCE based electrochemical sensor can detect CIP at a lower concentration and has a better LOD than the previous methods, which was probably credited with the high adsorption capacity, high porosity, two dimensional amphiphilicity and interface surface

Table 1 The accuracy and precision results of CIP determination in spiked milk as real sample

\begin{tabular}{llll}
\hline Spiked CIP $(\boldsymbol{\mu M})$ & $\begin{array}{l}\text { Detected CIP } \\
(\boldsymbol{\mu M})\end{array}$ & Recovery (\%) & RSD (\%) \\
\hline 1.0 & 0.81 & 81.0 & 4.6 \\
5.0 & 4.43 & 88.6 & 2.6 \\
10.0 & 9.54 & 95.4 & 3.7 \\
\hline
\end{tabular}

area of GO modified electrode. Moreover, the low toxic organic solvent was used in electrode preparation instead of hazardous organic solvent in other methods. The simple procedure of SPCE modification, better reliability and stability of electrode and better repeatability of method make the proposed GO-SPCE a feasible electrochemical sensor for CIP detection in milk sample even if there is possible interference in real sample.

\section{Conclusions}

In this study, graphene oxide with amphiphilicity, negative charges and large specific surface area was used to modify the screen-printed electrode to enhance the sensitivity of signal response and simplify the procedure of application. A novel method for CIP determination was developed based on monitoring the peak current response of the complexation of CIP with $\mathrm{Mn}^{2+}$ by modified GO-SPCE. Moreover, the developed method was applied to detect CIP in real milk samples and each evaluation parameters of method met the testing requirements. These results indicated that the proposed GOSPCE method is feasible and has potential to be applied in CIP residue analysis in real sample.

\section{Abbreviations}

CIP: Ciprofloxacin; SPCE: Screen-printing carbon electrode; GO-SPCE: Graphene oxide modified screen-printing carbon electrode; CV: Cyclic voltammetry; LOD: Limit of detection.

\section{Acknowledgements}

Not applicable.

\section{Authors' contributions}

$P G, H L$ and $Q X$ proposed, planned, and designed the project. MP and PG performed the material preparation and electrochemical tests. MP, PG, HL, JL, and QX contributed to writing the manuscript. All authors read and approved the final manuscript.

\section{Funding}

This work was supported by Science and Technology Planning Project of Guangzhou (201704030023, 201807010077).

\section{Availability of data and materials}

Not applicable.

Table 2 Comparison of analytical performance of different modified electrodes for CIP

\begin{tabular}{llll}
\hline Modified electrode & Linear range $(\mu \mathrm{M})$ & LOD $(\boldsymbol{\mu M})$ & References \\
\hline MWCNT/GCE & $40-1000$ & 6 & Garrido et al. (2016) \\
DNA biosensor & $40-80$ & 24 & Garbellini et al. (2015) \\
Chitosan/Fe $\mathrm{O}_{4} / \mathrm{CPE}$ & $6-75$ & 2 & Dehdashtian et al. (2016) \\
$\mathrm{GO} / \mathrm{SPCE}$ & $1-8$ & 0.3 & This work \\
\hline
\end{tabular}




\section{Declaration}

\section{Competing interests}

The authors have declared no conflict of interest.

\section{Author details}

${ }^{1}$ Guangdong Institute of Modern Agricultural Equipment, No. 261 Wushan Road, Tianhe District, Guangzhou 510630, China. ${ }^{2}$ Guangzhou Joinken Network Technology Development Co., Ltd., Guangzhou 510630, China.

Received: 22 September 2021 Accepted: 14 November 2021

Published online: 25 November 2021

\section{References}

Abdulghani AJ, Jasim HH, Hassan AS. Determination of tetracycline in pharmaceutical preparation by molecular and atomic absorption spectrophotometry and high performance liquid chromatography via complex formation with $\mathrm{Au}(\mathrm{III})$ and $\mathrm{Hg}(\mathrm{II})$ ions in solutions. Int J Anal Chem. 2013;2013:1-11. https://doi.org/10.1155/2013/305124.

Acuautla M, Bernardini S, Gallais L, Fiorido T, Patout L, Bendahan M. Ozone flexible sensors fabricated by photolithography and laser ablation processes based on ZnO nanoparticles. Sens Actuators B Chem. 2014;203:602-11. https://doi.org/10.1016/j.snb.2014.07.010.

Ambaye AD, Kefeni KK, Mishra SB, Nxumalo EN, Ntsendwana B. Recent developments in nanotechnology-based printing electrode systems for electrochemical sensors. Talanta. 2021;225: 121951. https://doi.org/10. 1016/j.talanta.2020.121951.

Aminov RI. The role of antibiotics and antibiotic resistance in nature. Environ Microbiol. 2009;11(12):2970-88. https://doi.org/10.1111/j.1462-2920. 2009.01972.x.

Ankireddy K, Menon AK, lezzi B, Yee SK, Losego MD, Jur JS. Electrical conductivity, thermal behavior, and Seebeck coefficient of conductive films for printed thermoelectric energy harvesting systems. J Electron Mater. 2016;45(11):5561-9. https://doi.org/10.1007/s11664-016-4780-2.

Bekoe SO, Bak SA, Björklund E, Krogh KA, Okine N, Adosraku RK, Hansen M. Determination of thirteen antibiotics in drug products - a new LC-MS/MS tool for screening drug product quality. Anal Methods. 2014;6(15):5847-55. https://doi.org/10.1039/c4ay00748d.

Bitew Z, Amare M. Recent reports on electrochemical determination of selected antibiotics in pharmaceutical formulations: a mini review. Electrochem Commun. 2020;121: 106863. https://doi.org/10.1016/j.elecom. 2020.106863

Cheng D, Ngo HH, Guo W, Chang SW, Nguyen DD, Liu Y, Wei D. A critical review on antibiotics and hormones in swine wastewater: water pollution problems and control approaches. J Hazard Mater. 2020;387: 121682. https:// doi.org/10.1016/j.jhazmat.2019.121682.

Dehdashtian S, Gholivand MB, Shamsipur M, Azadbakht A, Karimi Z. Fabrication of a highly sensitive and selective electrochemical sensor based on chitosan-coated $\mathrm{Fe}_{3} \mathrm{O}_{4}$ magnetic nanoparticle for determination of antibiotic ciprofloxacin and its application in biological samples. Can J Chem. 2016;94(10):803-11. https://doi.org/10.1139/cjc-2016-0129.

Gan T, Hu S. Electrochemical sensors based on graphene materials. Microchim Acta. 2011;175(1-2):1-19. https://doi.org/10.1007/s00604-011-0639-7.

Garbellini GS, Rocha-Filho RC, Fatibello-Filho O. Voltammetric determination of ciprofloxacin in urine samples and its interaction with dsDNA on a cathodically pretreated boron-doped diamond electrode. Anal Methods. 2015;7(8):3411-8. https://doi.org/10.1039/c5ay00625b.

Garrido JMPJ, Melle-Franco M, Strutyński K, Borges F, Brett CMA, Garrido EMPJ. $\beta$-Cyclodextrin carbon nanotube-enhanced sensor for ciprofloxacin detection. J Environ Sci Health Part A. 2016;52(4):313-9. https://doi.org/ 10.1080/10934529.2016.1258864.

Ghanbari K, Hajian A. Electrochemical characterization of Au/ZnO/PPy/ RGO nanocomposite and its application for simultaneous determination of ascorbic acid, epinephrine, and uric acid. J Electroanal Chem. 2017;801:466-79. https://doi.org/10.1016/j.jelechem.2017.07.024.

Hayat A, Haider W, Rolland M, Marty JL. Electrochemical grafting of long spacer arms of hexamethyldiamine on a screen printed carbon electrode surface: application in target induced ochratoxin A electrochemical aptasensor. Analyst. 2013;138(10):2951. https://doi.org/10.1039/c3an0 0158j.

Li M, Li DW, Xiu G, Long YT. Applications of screen-printed electrodes in current environmental analysis. Curr Opin Electrochem. 2017;3(1):137-43. https://doi.org/10.1016/j.coelec.2017.08.016

Liu H, Wang H, Sunderland VB. An isocratic ion exchange HPLC method for the simultaneous determination of flucloxacillin and amoxicillin in a pharmaceutical formulation for injection. J Pharm Biomed Anal. 2005;37(2):395-8. https://doi.org/10.1016/j.jpba.2004.10.029.

Mendez ASL, Weisheimer V, Oppe TP, Steppe M, Schapoval EES. Microbiological assay for the determination of meropenem in pharmaceutical dosage form. J Pharm Biomed Anal. 2005;37(4):649-53. https://doi.org/10.1016/j. jpba.2004.11.030.

Pumera M, Ambrosi A, Bonanni A, Chng ELK, Poh HL. Graphene for electrochemical sensing and biosensing. TrAC Trends Anal Chem. 2010;29(9):954-65. https://doi.org/10.1016/j.trac.2010.05.011.

Shan J, Liu Y, Li R, Wu C, Zhu L, Zhang J. Indirect electrochemical determination of ciprofloxacin by anodic stripping voltammetry of $\mathrm{Cd}(\mathrm{II})$ on graphenemodified electrode. J Electroanal Chem. 2015;738:123-9. https://doi.org/ 10.1016/j.jelechem.2014.11.031.

Tortorich R, Shamkhalichenar H, Choi JW. Inkjet-printed and paper-based electrochemical sensors. Appl Sci. 2018;8(2):288. https://doi.org/10.3390/ app8020288.

Trojanowicz M. Impact of nanotechnology on design of advanced screenprinted electrodes for different analytical applications. TrAC Trends Anal Chem. 2016;84:22-47. https://doi.org/10.1016/j.trac.2016.03.027.

Van Doorslaer X, Dewulf J, Van Langenhove H, Demeestere K. Fluoroquinolone antibiotics: an emerging class of environmental micropollutants. Sci Total Environ. 2014;500-501:250-69. https://doi.org/10.1016/j.scitotenv.2014. 08.075 .

Wang Y, Shen C, Zhang M, Zhang BT, Yu YG. The electrochemical degradation of ciprofloxacin using a $\mathrm{SnO} 2-\mathrm{Sb} / \mathrm{Ti}$ anode: influencing factors, reaction pathways and energy demand. Chem Eng J. 2016;296:79-89. https://doi. org/10.1016/j.cej.2016.03.093.

Wei K, Sun J, Gao Q, Yang X, Ye Y, Ji J, Sun X. 3D "honeycomb" cell/carbon nanofiber/gelatin methacryloyl (GeIMA) modified screen-printed electrode for electrochemical assessment of the combined toxicity of deoxynivalenol family mycotoxins. Bioelectrochemistry. 2021;139: 107743. https://doi.org/10.1016/j.bioelechem.2021.107743.

Wu Y, Deng P, Tian Y, Ding Z, Li G, Liu J, He Q. Rapid recognition and determination of tryptophan by carbon nanotubes and molecularly imprinted polymer-modified glassy carbon electrode. Bioelectrochemistry. 2020;131: 107393. https://doi.org/10.1016/j.bioelechem.2019.107393.

Zhang Y, Cai X, Lang X, Qiao X, Li X, Chen J. Insights into aquatic toxicities of the antibiotics oxytetracycline and ciprofloxacin in the presence of metal: complexation versus mixture. Environ Pollut. 2012;166:48-56. https://doi. org/10.1016/j.envpol.2012.03.009.

Zhang J, Yan M, Yuan X, Si M, Jiang L, Wu Z, Zeng G. Nitrogen doped carbon quantum dots mediated silver phosphate/bismuth vanadate Z-scheme photocatalyst for enhanced antibiotic degradation. J Colloid Interface Sci. 2018;529:11-22. https://doi.org/10.1016/j.jcis.2018.05.109.

Zhang L, Gao Y, Yue Q, Zhang P, Wang Y, Gao B. Prepartion and application of novel blast furnace dust based catalytic-ceramic-filler in electrolysis assisted catalytic micro-electrolysis system for ciprofloxacin wastewater treatment. J Hazard Mater. 2020;383: 121215. https://doi.org/10.1016/j. jhazmat.2019.121215.

Zhao Y, Zhou J, Jia Z, Huo D, Liu Q, Zhong D, Hou C. In-situ growth of gold nanoparticles on a 3D-network consisting of a MoS2/rGO nanocomposite for simultaneous voltammetric determination of ascorbic acid, dopamine and uric acid. Microchim Acta. 2019;186(2):1-10. https://doi. org/10.1007/s00604-018-3222-7.

Zheng Y, Qiu S, Deng F, Zhu Y, Li G, Ma F. Three-dimensional electro-Fenton system with iron foam as particle electrode for folic acid wastewater pretreatment. Sep Purif Technol. 2019;224:463-74. https://doi.org/10. 1016/j.seppur.2019.05.054.

\section{Publisher's Note}

Springer Nature remains neutral with regard to jurisdictional claims in published maps and institutional affiliations. 